\title{
Pediatric Patients with Marfan Syndrome: Frequency of Dural Ectasia and its Correlation with Common Cardiovascular Manifestations
}

\author{
Pädiatrische Patienten mit Marfan-Syndrom: Prävalenz der \\ Duraektasie und ihre Korrelation mit den häufigsten \\ kardiovaskulären Manifestationen.
}

Authors

Affiliations

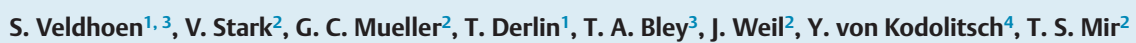

Department of Diagnostic and Interventional Radiology, University Medical Center Hamburg-Ependorf, Hamburg, Germany 2 Department of Pediatric Cardiology, University Heart Center Hamburg, Germany

3 Department of Diagnostic and Interventional Radiology, University Medical Center Würzburg, Germany

${ }^{4}$ Department of Cardiology, University Heart Center Hamburg, Germany
Key words

- aorta

- cardiac

- genetic defects

- echocardiography

- MR imaging

connective tissue disorders

received 17.1.2013

accepted 3.7.2013

Bibliography

Dol http://dx.doi.org/

10.1055/s-0033-1350421

Published online: 16.9.2013

Fortschr Röntgenstr 2014; 186 :

61-66 @ Georg Thieme Verlag

KG Stuttgart · New York .

ISSN 1438-9029

\section{Correspondence}

\section{Herr Dr. Simon Veldhoen}

Institut für Röntgendiagnostik, Universitätsklinikum Würzburg Josef-Schneider-Straße 2

97080 Würzburg

Germany

Tel.: ++ 49/17/02414272

Fax: ++ 49/93/1201634001

Simon.Veldhoen@Roentgen.

Uni-Wuerzburg.de

\section{Zusammenfassung}

$\nabla$

Einleitung: Das Marfan-Syndrom (MFS) ist eine genetische Erkrankung des Bindegewebes. Die Aortenwurzel-Dilatation ist ein Hauptkriterium der Gent-Nosologie. Die Duraektasie und der Mitralklappenprolaps (MVP) tragen zu einem systemischen Score der Nosologie bei. An einem rein pädiatrischen Patientenkollektiv wird die Prävalenz der Duraektasie ermittelt und auf Korrelationen zu kardiovaskulären Manifestationen hin untersucht.

Material und Methoden: Von 119 pädiatrischen Patienten, die die lokale Marfan-Sprechstunde konsultierten, konnten wir 31 MFS-Betroffene einschließen, die eine MRT zum Ausschluss einer Duraektasie erhalten hatten. Jeder Patient wurde entsprechend der Gent-Nosologie untersucht. Zur Vermessung der Aortenwurzel und zur Detektion des MVP sowie der Mitrainsuffizienz wurde die Echokardiografie verwendet. Für die Bewertung der Diameter der Aortenwurzel wurden z-scores berechnet. Per MRT wurde die Duralsackratio (DSR) bestimmt.

Ergebnisse: Die Prävalenz der Duraektasie lag bei $90,3 \%$, der Aortenwurzeldilatation (z-score $\geq 2$ ) bei $32,2 \%$, des MVP bei $64,5 \%$ und der Mitralinsuffizienz bei 51,6\%. Die DSR von L5 zeigte eine Korrelation zu den intraindividuellen z-scores (Regressionskoeffizient 3,62 $\pm 1,5 \quad[0,56 ; 6,68]$; $\mathrm{r}=0,17 ; \mathrm{p}=0,02 ; \mathrm{F}=5,84)$. Z-scores $\geq 2$ gingen in $100 \%$ mit einer Duraektasie einher, MVP in 95\% und die Mitralinsuffizienz in 100\%. Der MVP zeigte in $70 \%$ eine zusätzliche Mitralinsuffizienz. Zusammenfassung: Da die untersuchten kardialen Manifestationen in 95-100\% eine Koinzidenz mit der Duraektasie zeigen, sollte die MRT zur rein diagnostischen Bildgebung des Duralsackes für Verdachtsfälle vorbehalten bleiben, in denen keine kardialen Manifestationen nachweisbar

\section{Abstract \\ $\nabla$}

Purpose: Marfan syndrome (MFS) is a genetic disorder of the connective tissue. Aortic root dilation is a main criterion of the Ghent Nosology. Dural ectasia and the presence of mitral valve prolapse (MVP) contribute to its systemic score. The purpose of this study was to investigate the frequency of dural ectasia and its correlation with cardiovascular manifestations in a pediatric study population.

Patients and methods: 119 pediatric patients with confirmed or suspected MFS were examined in the local Marfan Clinic. 31 children with MFS who underwent magnetic resonance imaging (MRI) were included. Each patient was evaluated according to the Ghent nosology. Echocardiography was used to measure the aortic root diameter and assess the presence of MVP and mitral regurgitation. Z-scores were calculated for the evaluation of the aortic root diameters. MRI was performed to determine the dural sac ratio (DSR). Results: The prevalence of dural ectasia was $90.3 \%$, of aortic root dilation $32.2 \%$, of MVP $64.5 \%$ and of mitral regurgitation $51.6 \%$. DSR at L5 correlated with the intraindividual $z$-scores (slope, 3.62 \pm 1.5 [0.56; 6.68]; r =0.17; $\mathrm{p}=0.02$; $\mathrm{F}=5.84$ ). Z-scores $\geq 2$ were accompanied by dural ectasia in $100 \%$, MVP in $95 \%$ and mitral regurgitation in $100 \%$ of cases. MVP was accompanied by mitral regurgitation in $70 \%$ of cases.

Conclusion: As the examined cardiac manifestations show a coincidence with dural ectasia in $95-100 \%$ of cases, MRI for diagnostic dural sac imaging should be reserved for MFS suspicions with the absence of those manifestations in order to establish the diagnosis according to the Ghent criteria. Thus, the present study supports the recent downgrading of dural ectasia to a contributor to the systemic score. 
sind, um die Diagnose anhand der Gent-Nosologie zu etablieren. Daher bestätigt diese Studie die Herabstufung der Duraektasie durch die letzte Überarbeitung der Gent-Nosologie.

Key Points

- The prevalence of dural ectasia in children with MFS amounts to $90 \%$.

- Aortic root dilation, mitral valve prolapse and mitral regurgitation show a coincidence with dural ectasia in $95 \%-100 \%$ of children with MFS.

- MRI for diagnostic dural sac imaging should be reserved for pediatric MFS suspicions with absence of aortic root dilation, mitral valve prolapse and mitral regurgitation.

\section{Citation Format:}

- Veldhoen S, Stark V, Mueller GC et al. Pediatric Patients with Marfan Syndrome: Frequency of Dural Ectasia and its Correlation with Common Cardiovascular Manifestations. Fortschr Röntgenstr 2014; 186: 61-66

\section{Introduction \\ $\nabla$}

Marfan syndrome (MFS) is a genetic disorder of the connective tissue with autosomal-dominant inheritance. It is usually caused by mutations in the Fibrillin-1 gene (FBN1) and has a prevalence of one in $5000-10000$ individuals [1]. It causes a wide spectrum of symptoms of varying severity. Beside the ocular and skeletal system, the cardiovascular manifestations with their life-threatening complications are the focus of diagnostics and monitoring. Progressive dilation of the aortic root within the region of the sinuses of Valsalva is the most common complication. It has the potential to evoke aortic valve dysfunction and aortic dissection, which is the main cause of death in undetected Marfan syndrome [2]. The presence of mitral valve prolapse (MVP) represents another frequent cardiac manifestation. It is associated with an increased risk of progression to severe mitral valve regurgitation and endocarditis in adults and is therefore an important cardiac feature of MFS [3]. In consideration of the life expectancy of 32 years without therapy, early diagnosis is a key issue in the medical treatment of MFS [2]. Although there are molecular tests for FBN1 mutations, diagnosis also depends on clinical symptoms because of individual differences in the severity of the associated phenotype of a single mutation $[4,5]$. Furthermore, a pathognomonic mutation cannot be found in every individual. The Ghent nosology, which was recently revised, summarizes the typical symptoms and allows a standardized and reproducible diagnosis of MFS [6]. Lumbosacral dural ectasia contributes to the systemic score of the Ghent nosology. It is defined by a disparity between the diameters of the dural sac and the vertebral body of the associated spine segment $[7,8]$. Beside reports of lower back pain associated with dural ectasia and development of anterior meningoceles, follow-up studies did not reveal complications of dural ectasia, e.g. spondylolisthesis or scoliosis, thus expressing its mainly diagnostic relevance [9-11]. Aortic root dilation and the presence of MVP are also considered within the Ghent nosology. The purpose of this study was to investigate the frequency of dural ectasia and its correlation with frequent cardiovascular manifestations in an exclusive pediatric study collective with confirmed MFS. The latest downgrading of dural ectasia as a diagnostic criterion of MFS in the recently revised Ghent nosology will also be evaluated.

\section{Patients and Methods}

$\nabla$

\section{Study population}

We investigated 119 pediatric patients with confirmed or suggested Marfan syndrome, who attended the local Marfan Clinic.
All patients underwent a standardized diagnostic program involving the departments of orthopedics, ophthalmology, radiology and pediatric cardiology of the University Medical Center and the University Heart Center. Each patient was evaluated according to the Ghent criteria [6]. Of these 119 patients, 31 children $(\mathrm{m}=16 ; \mathrm{f}=15$; age $1-18$ years; mean age 11.5 years $)$ were diagnosed with MFS and underwent magnetic resonance imaging (MRI) for the diagnosis of dural ectasia, which were the two conditions for inclusion into the study group ( $\bullet$ Table 1 ). All patients in the study group underwent genetic testing with the result of FBN-1 mutation. 19 children were naive to aortoprotective pharmacotherapy, 7 were treated with $\beta$-blockers and 5 with AT1 antagonists (Valsartan).

Following informed consent and approval by the institutional review board, the study was performed according to the Declaration of Helsinki [12].

\section{Measuring of the aortic root and the mitral valve}

Two-dimensional echocardiography was used to measure the diameters of the aortic root in the parasternal long-axis orientation ( $\bullet$ Fig. 1a). The body surface was calculated using the Dubois formula [13]. Aortic root dilation was determined by the presence of a measurable disproportion between the diameter of the sinuses of Valsalva and the body surface. Z-scores were used to detect those disproportions with $\mathrm{z}$ defined as the number of standard deviations greater than or less than the predicted mean diameter of healthy children as described elsewhere [14]. Z-scores $\geq 2$ were defined as aortic root dilation. For evaluation of echocardiographic measures, Roman et al. and Gautier et al. published nomograms illustrating the relationship between aortic root and body surface during adolescence ( $\bullet$ Fig. 2, 3) [14, 15]. M-mode, two-dimensional and color-coded transthoracic echocardiography was used to determine the presence of MVP. Any late systolic prolapse $>2 \mathrm{~mm}$ on M-mode or leaflet displacement $>2 \mathrm{~mm}$, irrespective of a leaflet thickness $\leq 5 \mathrm{~mm}$ on two-dimen-

Table 1 Study population.

Tab. 1 Studienpopulation.

\begin{tabular}{|lc|}
\hline total & 31 \\
\hline female & 15 \\
\hline male & 16 \\
\hline age range (yrs) & $1-18$ \\
\hline mean age (yrs) & 11.5 \\
\hline age $0-1$ yr & 0 \\
\hline age $1-5$ yrs & 2 \\
\hline age $6-10$ yrs & 13 \\
\hline age $11-18$ yrs & 16 \\
\hline
\end{tabular}



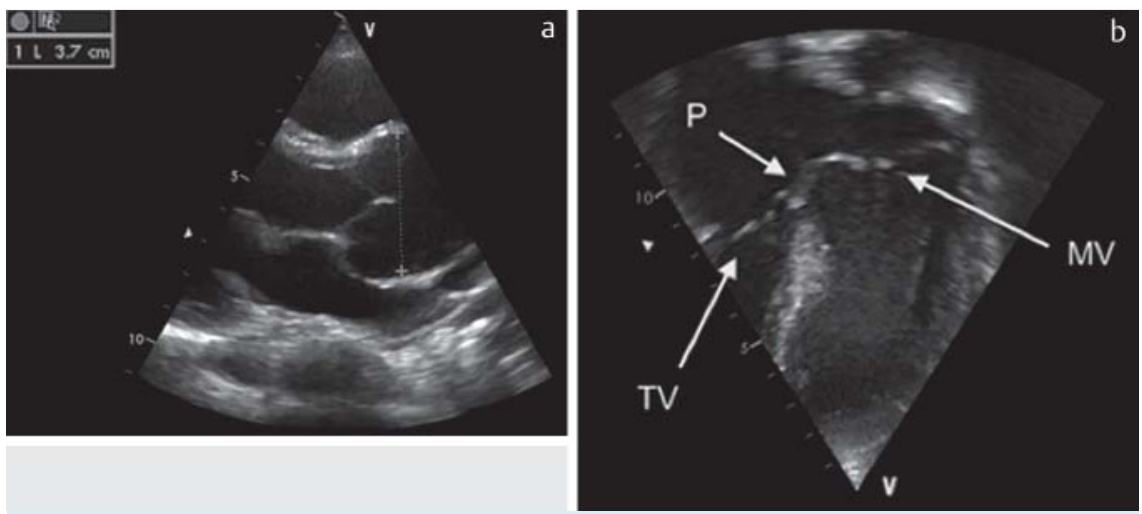

Fig. 1 a Two-dimensional echocardiography was used to measure the diameters of the aortic root in the parasternal long-axis orientation, e. g. the bulbus diameter in an 8-year-old female. b Two-dimensional echocardiography from the apical four-chamber view was used to determine MVP. Compared to the tricuspid valve level, the mitral valve shows a distinct prolapse. $M V=$ mitral valve; $T V=$ tricuspid valve; $\mathrm{P}=$ prolapse

Abb. 1 a Die zweidimensionale Echokardiografie in der parasternalen langen Achse wurde für die Vermessung der Aortenwurzel verwendet, hier als Beispiel bei einem achtjährigen Mädchen. b Die zweidimensionale Echokardiografie im Vierkammerblick wurde verwendet, um das Vorhandensein eines MVP zu überprüfen. Verglichen mit der Trikuspidalklappen-Ebene zeigt sich hier ein deutlicher Prolaps der Mitralklappe. MV = Mitralklappe, TV=Trikuspidalklappe, $\mathrm{P}=$ Prolaps.
Prevalence of aortic root dilation and correlation to dural ectasia $32.3 \%(n=10)$ of the patients showed pathologic $z$-scores $\geq 2$ at the sinuses of Valsalva, defined as dilation of the aortic root. $100 \%(n=10)$ of the study population with a pathologic z-score at the sinuses of Valsalva presented with dural ectasia at L5 or S1. For L5, dural ectasia was found in $100 \%(n=10)$ of the cases and for $\mathrm{S} 1$ in $80.0 \%(n=8)$ of the cases.

Linear regression analysis showed a regression coefficient (slope) of $3.62 \pm 1.5$ $[0.56 ; 6.68]$ with a correlation coefficient of 0.17 between the intraindividual $z$ scores at the sinuses of Valsalva and the DSR at L5 $(p=0.02 ; F=5.84)$. No similar dependence was found for $\mathrm{S} 1$. The regression coefficient was $1.32 \pm 1.0 \quad[-0.72$; 3.36] with a correlation of 0.06 ( $p>0.05$; $\mathrm{F}=1.75$ ), respectively. Analyses of subgroups based on pharmacotherapy status (no therapy, $\beta$-blockers, AT1 antagonists) revealed no significant relationship. sional echocardiography from the apical four-chamber view, was used to determine MVP ( $\bullet$ Fig. 1b) [6, 16-18]. The presence of mitral valve regurgitation was also recorded.

\section{Measuring of the dural sac}

MRI was performed to detect lumbosacral dural ectasia [19]. Therefore, the sagittal dural sac diameter was divided by the midsagittal vertebral body diameter of the associated spine segment to calculate the dural sac ratio (DSR) ( Fig. 4) [20]. According to Habermann et al., cut-off values for the presence of dural ectasia of 0.42 at the level of L5 and 0.51 at the level of S1 were used [7].

\section{Statistical analysis}

Linear regression analysis and Pearson's correlation were used to test for dependences between the aortic root diameter, mitral valve prolapse, mitral regurgitation and the dural sac ratio. In addition, the F-test was used to determine the F-value. P-values $<0.05$ were considered statistically significant. Quantitative data is presented as absolute numbers or as mean values with their standard deviation. In part, we added confidence intervals in square brackets. Relative data is presented in percentage or mentioned explicitly. Filemaker software vers. 10 pro advanced was used for data collection. Statistical analysis was performed using GraphPad Prism vers. 5.0 and Microsoft Excel 2011. Figures were created using GraphPad Prism vers. 5.0 and tables were created using Microsoft Excel 2011.

\section{Results}

$\nabla$

\section{Prevalence of dural ectasia}

Using the cut-off values defined by Haberman et al. [7], a pathological DSR was seen at spine segment L5 in 28 children (90.3\%) with MFS and at the level of S1 in 26 patients (83.9\%) $\bullet$ Table 2.

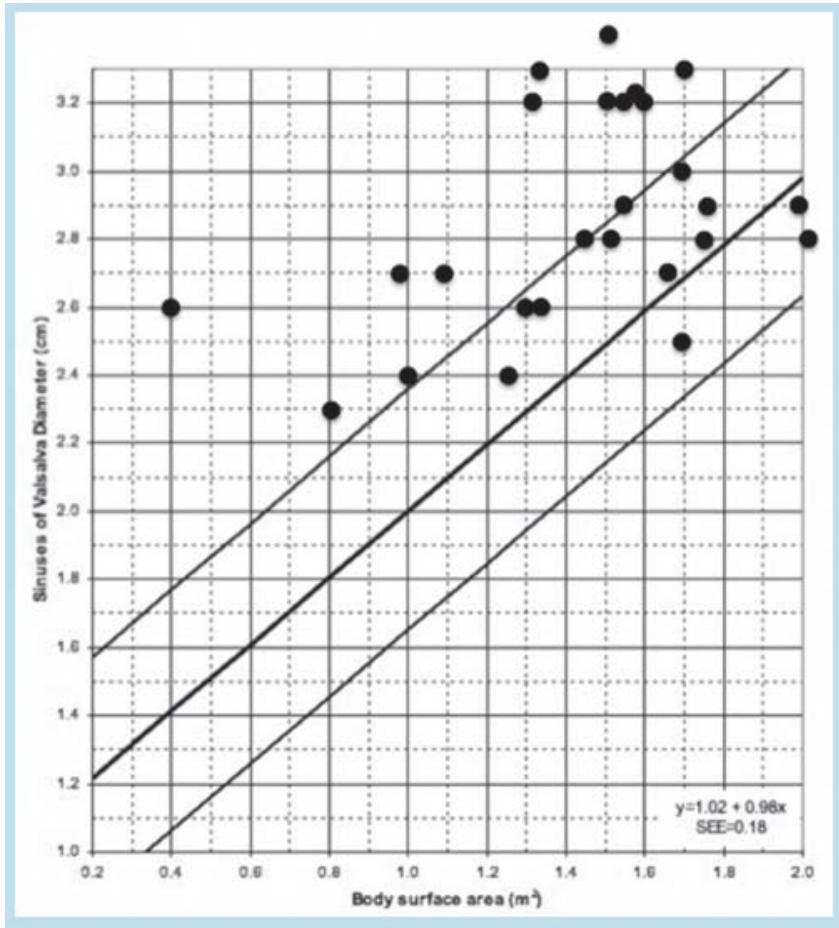

Fig. 2 Nomogram of physiological aortic root dimensions in infants and children. The central line shows the expected aortic root diameter in dependence of the body surface and is flanked by the $95 \%$ confident interval. The measuring points show the increase of aortic root diameters in children with MFS [15]. 5 patients are not mapped because their measurements exceeded the nomogram.

Abb. 2 Nomogramm der Aortenwurzel-Diameter bei Heranwachsenden. Die mittlere Linie zeigt den erwarteten Aortenwurzel-Diameter in Abhängigkeit von der Körperoberfläche und ist vom 95\%-Konfidenzintervall flankiert [15]. Die Messpunkte zeigen die erhöhten Diameter der Aortenwurzel bei den an MFS erkrankten Kindern. Die Messpunkte von 5 Patienten sind nicht abgebildet, da sie außerhalb des Nomograms lagen. 


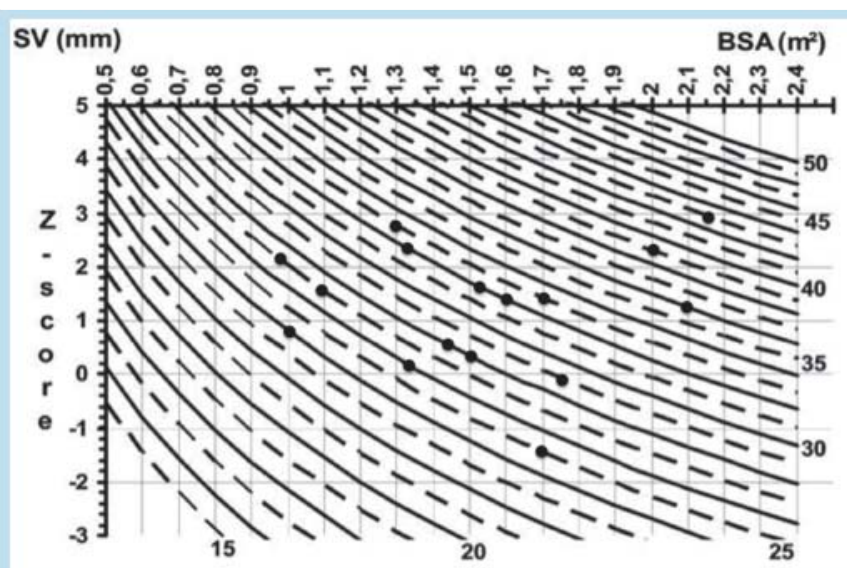

Fig. 3 Left: Nomogram for determination of the z-score in dependence of the echocardiographic measurements at the Sinus of Valsalva and the body surface for male children. Right: Nomogram for determination of the zscore in dependence of the echocardiographic measurements at the Sinus of Valsalva and the body surface for female children. Measuring points show the results of the study population. 1 patient is not mapped in the female nomogram because of a $z$-score $>5$. [14]

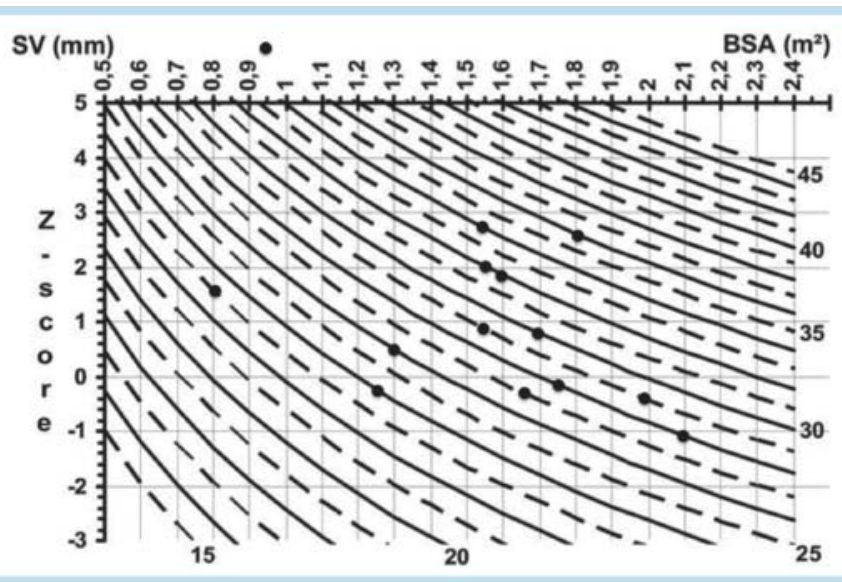

Abb. 3 Links: Nomogram zur Bestimmung des z-scores für Jungen unter Verwenduung des echokardiografisch vermessenen Diameters an den Sinus Valsalvae und der errechneten Körperoberfläche. Rechts: Nomogram zur Bestimmung des z-scores für Mädchen unter Verwendung des echokardiografisch vermessenen Diameters an den Sinus Valsalvae und der errechneten Körperoberfläche. [14] Die Messpunkte zeigen die Ergebnisse der Studienpopulation. 1 Messpunkt ist nicht eingezeichnet, da der z-score $>5$ lag.

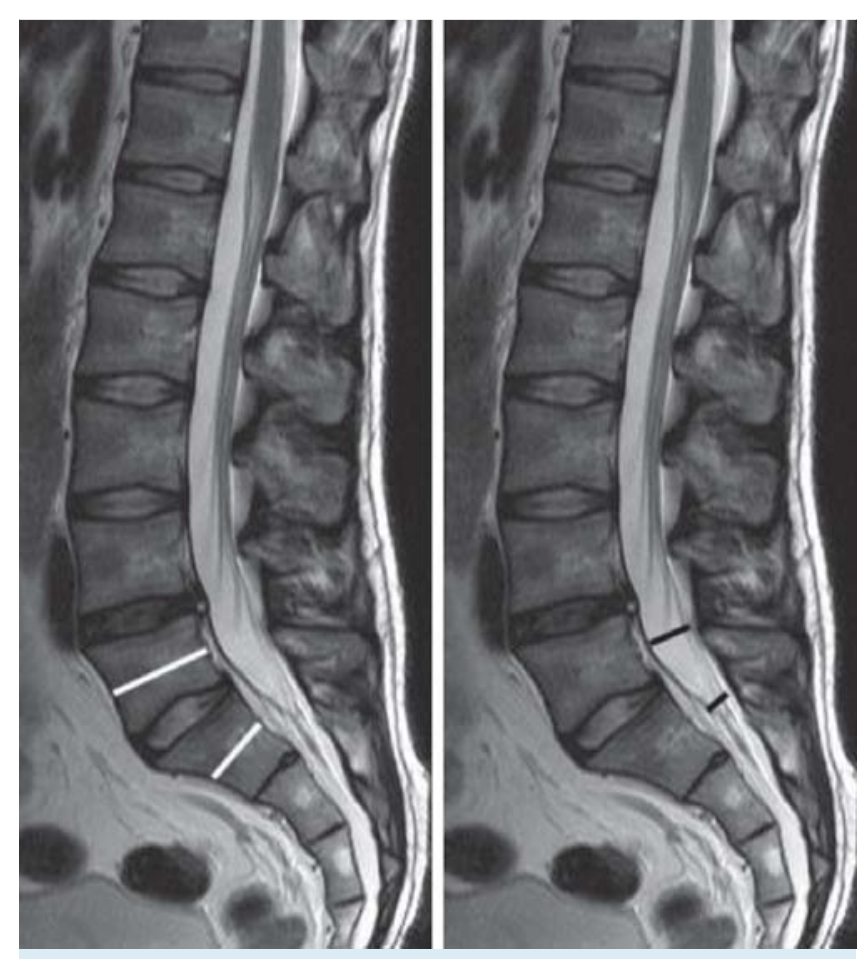

Fig. 4 Sagittal T2-weighted spin-echo MR images (TR $4200 \mathrm{msec} / \mathrm{TE}$ $120 \mathrm{msec}$ ) of the lumbosacral spine show measurement lines of, left, vertebral body diameters, and right, dural sac diameters.

Abb. 4 Die sagittalen T2-gewichteten spin-echo MR-Bilder (TR $4200 \mathrm{msec}$ ) TE $120 \mathrm{msec}$ ) des lumbosakralen Überganges zeigen die Messlinien des Wirbelkörper-Diameters (links) und des Duralsack-Diameters (rechts).

No significant correlations between the DSR at spine segment L5 or S1 and the measured absolute diameter of the aortic root at the sinuses of Valsalva were found. Particularly, the regression coefficient for L5 was $-0.01 \pm 0.48[-0.98 ; 0.96]$ and the correlation coefficient was -0.005 ( $p>0.05 ; F=0.0006)$. For $S 1$, the re- gression coefficient was $0.23 \pm 0.29[-0.37 ; 0.84]$ and the correlation coefficient was 0.15 ( $\mathrm{p}>0.05 ; \mathrm{F}=0.63$ ).

Prevalence of MVP and correlation to dural ectasia $64.5 \%(n=20)$ of the children in the study collective fulfilled the criteria of MVP within echocardiography from the apical fourchamber view Table 2. 95\% $(n=19)$ of the children with MVP presented with dural ectasia at L5 or S1. At L5, dural ectasia was found in $95 \%(n=19)$ of the cases and at S1 in $90 \%(n=18)$ of the cases.

Regarding the total study population, linear regression analyses provided no significant dependences between the DSR at spine segment L5 or S1 and the presence of MVP. For L5, a regression coefficient of $0.12 \pm 0.50[-0.91 ; 1.14]$ with a correlation of 0.04 ( $p>0.05 ; F=0.05$ ) was calculated. For $\mathrm{S} 1$, the regression coefficient was $0.21 \pm 0.31[-0.42 ; 0.85]$ with a correlation coefficient of $0.13(p>0.05 ; F=0.47)$. Analyses of subgroups based on pharmacotherapy status (no therapy, $\beta$-blockers, AT1 antagonists) revealed no alterations concerning the results. No significant relationships were found.

\section{Prevalence of mitral regurgitation and correlation}

to dural ectasia

$51.6 \%(n=16)$ of the diagnosed children presented with first-degree mitral valve regurgitation. In the case of detected MVP, additional mitral regurgitation was found in $70 \%(n=14$ of 20$)$ of the cases. No mitral regurgitation greater than first-degree was observed in the study population. $100 \%(n=16)$ of the study population with diagnosed mitral regurgitation presented with dural ectasia at L5 as well as S1.

Regarding the total study population, linear regression analyses showed no significant dependences between the DSR at spine segment L5 or S1 and the presence of mitral regurgitation. For L5, a regression coefficient of $0.3 \pm 0.52[-0.76 ; 1.36]$ with a correlation of 0.01 ( $p>0.05 ; \mathrm{F}=0.34)$ was calculated. For $\mathrm{S} 1$, the regression coefficient was $0.49 \pm 0.31[-0.15 ; 1.14]$ with a correlation coefficient of 0.08 ( $p>0.05 ; F=2.47)$. Analyses of subgroups based on pharmacotherapy status (no therapy, $\beta$-blockers, AT1 
Table 2 Aortic root diameter, presence of MVP and dural sac ratios for L5 and $\mathrm{S} 1$ in 31 patients.

Tab. 2 Durchmesser der Aortenwurzel, Vorhandensein eines MVP und die Duralsackratio von L5 und S1 bei 31 Patienten.

\begin{tabular}{|c|c|c|c|c|}
\hline $\begin{array}{l}\text { patient } \\
\text { ID }\end{array}$ & $\begin{array}{l}\text { bulbus diameter } \\
(\mathrm{cm})\end{array}$ & $\begin{array}{l}\text { MVP } \\
(+\mid-)\end{array}$ & DSR L5 & DSR S1 \\
\hline 1 & 3.2 & + & 0.43 & 0.48 \\
\hline 2 & 2.7 & + & 0.56 & 0.52 \\
\hline 3 & 2.8 & + & 0.33 & 0.39 \\
\hline 4 & 3.9 & - & 0.5 & 0.6 \\
\hline 5 & 3.6 & + & 0.56 & 0.10 \\
\hline 6 & 2.5 & - & 0.30 & 0.40 \\
\hline 7 & 4.3 & + & 0.48 & 0.60 \\
\hline 8 & 2.7 & - & 0.62 & 0.74 \\
\hline 9 & 3.2 & + & 0.95 & 1.38 \\
\hline 10 & 3.3 & + & 0.63 & 0.80 \\
\hline 11 & 2.9 & - & 0.51 & 0.90 \\
\hline 12 & 3.4 & + & 0.60 & 0.60 \\
\hline 13 & 3.3 & + & 0.69 & 0.89 \\
\hline 14 & 3.2 & + & 0.60 & 1.30 \\
\hline 15 & 2.9 & - & 0.80 & 0.90 \\
\hline 16 & 3.0 & + & 0.52 & 0.70 \\
\hline 17 & 2.9 & + & 0.56 & 0.53 \\
\hline 18 & 2.4 & - & 0.52 & 0.55 \\
\hline 19 & 2.6 & + & 0.56 & 0.78 \\
\hline 20 & 2.6 & - & 1.09 & 1.08 \\
\hline 21 & 2.8 & + & 0.89 & 1.30 \\
\hline 22 & 3.6 & - & 0.45 & 0.50 \\
\hline 23 & 2.6 & + & 0.46 & 0.65 \\
\hline 24 & 3.2 & - & 0.70 & 1.20 \\
\hline 25 & 2.3 & + & 0.50 & 0.60 \\
\hline 26 & 3.2 & + & 0.47 & 0.52 \\
\hline 27 & 2.8 & + & 0.42 & 0.63 \\
\hline 28 & 2.7 & - & 0.36 & 0.41 \\
\hline 29 & 2.4 & + & 0.76 & 0.81 \\
\hline 30 & 2.8 & - & 0.48 & 0.52 \\
\hline 31 & 3.5 & + & 0.77 & 1.10 \\
\hline
\end{tabular}

antagonists) revealed no alterations concerning the results. No significant relationships were found.

\section{Discussion}

$\nabla$

Lumbosacral dural ectasia was a major criterion of the original Ghent nosology, but its importance has been downgraded in the latest revision in 2010. "Dural ectasia is a sensitive but not a specific sign of MFS and, as such, is no longer considered on equal footing with lens dislocation or aortic root enlargement" [6]. Accordingly, dural ectasia is no longer a major criterion of the Ghent nosology but now contributes to a score of systemic features [6, 21]. However, a pathognomonic mutation cannot be found in every individual with the disease and the detection of dural ectasia can still be essential to substantiate the clinical diagnosis of MFS in those cases as it is the second most common feature of the syndrome after aortic root dilation $[22,23]$. To our knowledge, no studies have investigated correlations between dural ectasia and cardiovascular manifestations within a pediatric patient population.

The high prevalence of lumbosacral dural ectasia in MFS patients has been known for years and is again confirmed by the present study that showed a pathologic DSR in $90.3 \%$ of the children [24]. The present study revealed no linear dependence between the dural sac ratio at spine segments L5 and S1 and the absolute diameter of the aortic root at the sinuses of Valsalva in pediatric patients with confirmed MFS. As Fattori et al. could not reveal a dependence concerning these measurements within a study that included 83 adult MFS patients, these results can be transferred to pediatric patients [10]. However, in pediatric medicine zscores gained acceptance in the evaluation of the aortic root during the last years due to consideration of normal aortic growth and gender by implementation of correction factors [14, 25]. Prospecting the relationship between those z-scores and the DSR revealed a correlation between the intraindividual z-score and the DSR at the spine level of L5. The DSR increased with the calculated $z$-score. However, with $r=0.17$ the observed correlation is moderate and a prediction of one parameter in dependence of the other is questionable for a single patient. Nonetheless, $100 \%$ of the examined children with diagnosed aortic root dilation by a z-score $\geq 2$ showed lumbosacral dural ectasia. Respectively, 95\% of the children with MVP and $100 \%$ with mitral regurgitation showed dural ectasia. Deduced from these results, additional imaging of the dural sac does not seem to be necessary in the case of aortic root dilation diagnosed by echocardiography during adolescence. Concerning very young children, this allows for abstaining from necessary sedation during MRI [26]. Nonetheless, in the case of MFS suspicion and the absence of aortic root dilation, dural imaging using MRI can be sensible to substantiate the clinical diagnosis. That raises the question as to how many patients require additional MR imaging of the dural sac. In this context, we observed dural ectasia in $58.1 \%$ of the children with FBN1 mutation and the absence of aortic root dilation. That underlines the necessity of additional dural imaging in those patients. Summarized, the authors recommend reserving dural imaging for children with MFS suspicion and the simultaneous absence of aortic root dilation.

The prevalence of mitral valve prolapse in MFS has been indicated within a range from $54 \%$ to $88 \%$ over all ages [ $27-29$ ]. The discrepancies between the cohorts could partly be explained by nonspecific diagnostic criteria being used in the past [30, 31]. In our study 20 children with MFS (64.5\%) presented with MVP matching this range. To our knowledge, there is only one more study that indicates the prevalence of MVP exclusively for pediatric patients with MFS. Rybczynski et al. conducted a large study among 204 MFS patients with a mean follow-up time of $4.4 \pm 4.3$ years [3]. In a subgroup of 23 patients aged $0-10$ years (mean $4.5 \pm 3$ years), the prevalence of MVP was $22 \%$. A subgroup of 35 patients aged $11-20$ years (mean $15.7 \pm 2.8$ years) showed a prevalence of $43 \%$. However, only $17 \%$ and $46 \%$, respectively, of patients in these subgroups had a proven FBN1 mutation, which might explain the difference in prevalence between the two studies. Interestingly, $95 \%$ of the children with diagnosed MVP presented with lumbosacral dural ectasia. Furthermore, the $70 \%$ concordance of MVP and first-degree mitral regurgitation is worth mentioning. The overall prevalence of mitral regurgitation was $51.6 \%$ and dural ectasia was found in all of these cases. The risk of severe mitral regurgitation and complications, e. g. endocarditis due to preceding MVP, is already known [3]. The present results show that the development of regurgitation seems to begin already in infancy and adolescence.

Summarized, the study revealed a correlation of the DSR at L5 and the intraindividual z-score of the echocardiographic aortic root measurements. In all children with pathologic z-scores $\geq 2$, additional dural ectasia was found. The prevalence of MVP was $64.5 \%$ and it was accompanied by dural ectasia in $95 \%$ of the 
cases. Coincidence of MVP and mitral regurgitation was found in $70 \%$ of the cases. Mitral regurgitation was accompanied by dural ectasia in $100 \%$ of the cases.

Deduced from these results, additional MRI with the single purpose of dural sac imaging should be reserved for MFS suspicions with the absence of aortic root dilation, mitral valve prolapse and mitral regurgitation as these cardiac manifestations show a coincidence with dural ectasia in $95-100 \%$ of cases. By this change in diagnostic approach, young children can forego the sedation necessary for MRI. In conclusion, the results support the recent downgrading of dural ectasia in the revised Ghent nosology and confirm the above-mentioned arguments of Loeys et al. [6].

\section{Study limitations}

The small pediatric study population as a limiting factor in our analyses is worth mentioning. Although a larger number of patients attended the pediatric Marfan Clinic, an MRI exam could not be performed for every patient. In part, MRI was not necessary to confirm the diagnosis of MFS or the children were too young, so that sedation would have been necessary to guarantee sufficient image quality. If sustainable, MRI exams were planned at a later time in those cases to avoid the complications of administering a sedative. Because of the small size of the study group, we continued the study to be able to perform a re-evaluation based on a larger number of pediatric patients. It would be useful to analyze different age-related study groups, which this study could not consider due to the small number of patients.

Another aspect that may have influenced the study is the use of transthoracic echocardiography, which is dependent on the examiner and the surrounding conditions. In particular, the examination of very young children is dependent on their cooperation and safe reproducibility of single exams cannot be guaranteed. MRI might be a useful alternative for ensuring consistent imaging quality but can be difficult to use on very young children due to the need for sedation [31].

\section{Conclusion \\ $\nabla$}

The presented study supports the recent downgrading of dural ectasia to a contributor to the systemic score in the revised Ghent nosology. Dural sac imaging should be reserved for MFS suspicions with the absence of aortic root dilation, mitral valve prolapse and mitral regurgitation. However, a re-evaluation based on a greater number of children, with age-related study groups as well as a comparison group of healthy children is desirable.

\section{References}

1 Rimoin DL, Pyeritz RE, Korf B. Emery \& Rimoin's Principles and Practice of Medical Genetics. Academic Press; 2013

2 Murdoch JL, Walker BA, Halpern BL et al. Life Expectancy and Causes of Death in the Marfan Syndrome. New England Journal of Medicine 1972; 286: 804-808

3 Rybczynski M, Mir TS, Sheikhzadeh S et al. Frequency and age-related course of mitral valve dysfunction in the Marfan syndrome. Am. J. Cardiol 2010; 106: 1048-1053

4 Robinson PN, Arteaga-Solis E, Baldock C et al. The molecular genetics of Marfan syndrome and related disorders. J. Med. Genet 2006; 43: 769787
5 Robinson PN, Godfrey M. The molecular genetics of Marfan syndrome and related microfibrillopathies. J. Med. Genet 2000; 37: 9-25

6 Loeys BL, Dietz HC, Braverman AC et al. The revised Ghent nosology for the Marfan syndrome. J. Med. Genet 2010; 47: 476-485

7 Habermann CR, Weiss F, Schoder $V$ et al. MR evaluation of dural ectasia in Marfan syndrome: reassessment of the established criteria in children, adolescents, and young adults. Radiology 2005; 234: 535-541

8 Lundby R, Rand-Hendriksen S, Hald JK et al. Dural ectasia in Marfan syndrome: a case control study. AJNR Am J Neuroradiol 2009; 30: 1534 1540

9 Ahn NU, Sponseller PD, Ahn UM et al. Dural ectasia is associated with back pain in Marfan syndrome. Spine 2000; 25: 1562 -1568

10 Fattori R, Nienaber CA, Descovich B et al. Importance of dural ectasia in phenotypic assessment of Marfan's syndrome. Lancet 1999; 354: 910-913

11 Mesfin A, Ahn NU, Carrino JA et al. Ten-year clinical and imaging follow-up of dural ectasia in adults with Marfan syndrome. Spine J 2013; 13: $62-67$

12 World Medical Association Declaration of Helsinki; 2008

13 Bois DuD, Bois DuEF. A formula to estimate the approximate surface area if height and weight be known. 1916. Nutrition 1989; 5: 303-311

14 Gautier M, Detaint D, Fermanian C et al. Nomograms for aortic root diameters in children using two-dimensional echocardiography. Am. J. Cardiol 2010; 105: 888-894

15 Roman MJ, Devereux RB, Kramer-Fox R et al. Two-dimensional echocardiographic aortic root dimensions in normal children and adults. Am. J. Cardiol 1989; 64: 507-512

16 Devereux RB, Kramer-Fox R, Shear MK et al. Diagnosis and classification of severity of mitral valve prolapse: methodologic, biologic, and prognostic considerations. Am. Heart J 1987; 113: 1265 - 1280

17 Freed LA, Levy D, Levine RA et al. Prevalence and clinical outcome of mitral-valve prolapse. N. Engl. J. Med 1999; 341: 1-7

18 De Backer J, Loeys B, Devos D et al. A critical analysis of minor cardiovascular criteria in the diagnostic evaluation of patients with Marfan syndrome. Genet. Med 2006; 8: 401 - 408

19 Eberhardt K, Ganslandt O, Stadlbauer A. Verbesserte MagnetresonanzMyelografie durch Bildfusion. Rofo 2013; 185: 333 - 339

20 Oosterhof T, Groenink M, Hulsmans FJ et al. Quantitative assessment of dural ectasia as a marker for Marfan syndrome. Radiology 2001; 220: 514-518

21 De Paepe A, Devereux RB, Dietz HC et al. Revised diagnostic criteria for the Marfan syndrome. Am. J. Med. Genet 1996; 62: 417-426

22 Ahn NU, Sponseller PD, Ahn UM et al. Dural ectasia in the Marfan syndrome: MR and CT findings and criteria. Genet. Med 2000; 2: 173-179

23 Rose PS, Levy HP, Ahn NU et al. A comparison of the Berlin and Ghent nosologies and the influence of dural ectasia in the diagnosis of Marfan syndrome. Genet. Med 2000; 2: 278-282

24 Knirsch W, Kurtz C, Häffner N et al. Dural ectasia in children with Marfan syndrome: a prospective, multicenter, patient-control study. Am. J. Med. Genet. A 2006; 140: 775-781

25 van Kimmenade RRJ, Kempers M, de Boer M-J et al. A clinical appraisal of different Z-score equations for aortic root assessment in the diagnostic evaluation of Marfan syndrome. Genet. Med 2013

26 Schaefer JF, Kramer U. Ganzkörper-MRT bei Kindern und Jugendlichen. Rofo 2011; 183: 24-36

27 van Karnebeek CD, Naeff MS, Mulder BJ et al. Natural history of cardiovascular manifestations in Marfan syndrome. Arch. Dis. Child 2001; 84: $129-137$

28 Pyeritz RE, Wappel MA. Mitral valve dysfunction in the Marfan syndrome. Clinical and echocardiographic study of prevalence and natural history. Am. J. Med 1983; 74: 797-807

29 Come PC, Fortuin NJ, White RI et al. Echocardiographic assessment of cardiovascular abnormalities in the Marfan syndrome. Comparison with clinical findings and with roentgenographic estimation of aortic root size. Am. J. Med 1983; 74: 465-474

30 Taub CC, Stoler JM, Perez-Sanz T et al. Mitral valve prolapse in Marfan syndrome: an old topic revisited. Echocardiography 2009; 26: $357-$ 364

31 Achenbach S, Barkhausen J, Beer M et al. Konsensusempfehlungen der DRG/DGK/DGPK zum Einsatz der Herzbildgebung mit Cimputertomografie und Magnetresonanztomografie. Rofo 2012: 345-368 